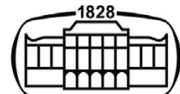

AKADÉMIAI KIADÓ

Journal of Behavioral Addictions

9 (2020) 3, 676-685

DOI:

$10.1556 / 2006.2020 .00032$

(c) 2020 The Author(s)

\section{FULL-LENGTH REPORT}

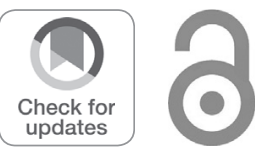

\title{
Relationship between Internet addiction, susceptible personality traits, and suicidal and self-harm ideation in Chinese adolescent students
}

\section{KUANG ${ }^{*}$, WO WANG ${ }^{2}, \mathrm{YAN} \mathrm{HUANG}^{3}$, XIAORONG $\mathrm{CHEN}^{2}, \mathrm{ZHEN} \mathrm{LV}{ }^{2}$, JUN CAO ${ }^{1}, \mathrm{MING} \mathrm{AI}^{1}$ and JIANMEI CHEN ${ }^{1}$}

\author{
${ }^{1}$ Department of Psychiatry, The First Affiliated Hospital of Chongqing Medical University, \\ Chongqing, China \\ ${ }^{2}$ Mental Health Center, University-Town Hospital of Chongqing Medical University, Chongqing, \\ China \\ ${ }^{3}$ GCP Office, Chongqing Traditional Chinese Medicine Hospital, Chongqing, China
}

Received: May 15, 2019 • Revised manuscript received: February 28, 2020; April 30, 2020 • Accepted: May 4, 2020

Published online: July 23, 2020

\begin{abstract}
Background and aims: Internet addiction (IA) is common among young students. This study aimed to examine the influence and mechanisms of IA and susceptible personality traits on the impact of suicidal ideation in adolescent students in China. Methods: This cross-sectional study (09/2012-09/2015) used stratified cluster sampling with "school type" for stratification; 136,266 students from 63 schools completed the questionnaire. Logistic regression analysis was performed to estimate the effect of IA (Young's Internet Addiction Test) and susceptible personality (Barratt impulsiveness scale, Buss \& Perry Aggression Questionnaire; and Eysenck Personality Questionnaire-R Short Scale) on suicidal ideation (Scale of Suicidal Ideation). Results: Suicidal ideation was observed in 20,218 (14.77\%) of the students, and IA was detected in 28,836 (21.16\%) subjects. Compared with those without IA, students with IA had a higher prevalence of suicidal ideation $(P<0.0001)$. No planning impulsiveness had a predictive effect on suicidal ideation in the impulsive personality trait, while in the aggressive personality trait, hostility and self-aggression had a predictive effect on suicidal ideation (all $P<0.0001$ ). High psychoticism and neuroticism were impact factors for suicidal ideation, but extroversion was a protective factor (all $P<0.0001$ ). Discussion: These results highlight the importance of assessing personality traits and reducing IA as a possible means of lessening suicidal ideation. Susceptible personality (such as high psychoticism, high neuroticism, and low extroversion) play a prominent role in influencing the probability of having suicidal behavior among those recently exposed to IA. Conclusions: IA and susceptible personality traits were significantly correlated with suicidal and self-harm ideation among adolescent students.
\end{abstract}

\section{KEYWORDS}

suicidal ideation, Internet, addiction, personality, aggressiveness, adolescent students

\section{INTRODUCTION}

*Corresponding author.

Suicidal ideation is the desire to commit suicide, but in which the individual does not take or implement any actual behaviors to do so. Suicidal ideation is characterized by covert, extensive, and sporadic thoughts about suicide (Klonsky, May, \& Saffer, 2016). Suicidal ideation is an important predictor of mental health problems and suicidal behavior (Thompson et al., 2012; Wong, Stewart, Ho, Rao, \& Lam, 2005; Zhang, Wang, Xia, Liu, \& 
Jung, 2012; Zhao et al., 2012). Studies in China have shown that suicidal ideation is prevalent among Chinese adolescents and the prevalence of suicidal ideation among students ranges from 10 to $40 \%$ or even higher (Li et al., 2014; Wang et al., 2019). In fact, suicide is the leading mortality cause among Chinese individuals of 15-34 years of age (Phillips, Li, \& Zhang, 2002). Social reasons might be involved in this phenomenon, including a heavy performance pressure for access to high-ranking universities and jobs. In addition, most of the actual college students were born in the "onechild policy" era and being from single-child families, they display impulsiveness and inability to withstand negative life compared with individuals of the same age but with siblings (Li et al., 2014; Luo, 2010; Wang, Yu, \& Tian, 2018).

Internet addiction (IA) is a relatively novel psychobehavioral disorder caused by the repeated or excessive use of the Internet, associated with a strong and irresistible desire to use the Internet as often as possible. A withdrawal response may even occur when Internet use is stopped or reduced, and both mental and somatic withdrawal symptoms may be present (Shaw \& Black, 2008). IA leads to significant social and psychological damage in individuals (Diomidous et al., 2016). It has been reported that in China, the rate of IA among teenagers is approximately $10-20 \%$ (Yang, Zhang, Hao, \& Sun, 2010; Yao, He, Ko, \& Pang, 2014a).

It is consistently reported that IA is closely related to the occurrence of suicidal ideation and behavior (Fu, Chan, Wong, \& Yip, 2010; Kim et al., 2006; Schilling, Aseltine, Glanovsky, James, \& Jacobs, 2009). According to some studies, personality is an important and relatively stable risk factor for suicide (Ai, Chen, \& Wangf, 2011; Yang, Jiang, \& Jia, 2017). Previous studies showed that the personality traits related to suicide mainly include neuroticism, psychoticism, extraversion, impulsiveness, and aggression (Dumais et al., 2005; Esposito, Spirito, Boergers, \& Donaldson, 2003; Heisel et al., 2006). Susceptible personality traits such as extraversion, neuroticism, and psychoticism are not only related to suicide but are also significantly related to IA (Gosling, Augustine, Vazire, Holtzman, \& Gaddis, 2011; Kayis et al., 2016; M. Z. Yao, He, Ko, \& Pang, 2014a; Y. Yao, Chen, \& Liu, 2014b).

Nevertheless, the exact relationship among these personality traits, IA, and suicidal ideation remains poorly understood. In addition, there might be an impact of the culture and society on this relationship. Therefore, it is particularly necessary to explore the effects of IA and different personality traits on suicidal ideation in different populations. Therefore, the aim of the present study was to explore the relationship between IA, susceptible personality traits, and suicidal ideation among Chinese adolescent students.

\section{METHODS}

\section{Study design and participants}

The present cross-sectional study was carried out from September 2012 to September 2015 (Huang, Kuang, Wang, Cao, \& Xu, 2019). All students were informed of the purpose of the study, the confidentiality of their personal information, and the principle of voluntary participation in the investigation.

This study used a stratified cluster sampling method in which the stratification factor was "school type". There were three types of schools based on their influence and affiliated institutions in Chongqing: universities, vocational colleges, and general middle schools (mainly high school). Sixty-three schools were selected according to the different types (13 universities, 21 vocational colleges, and 29 general middle schools) in Chongqing, China. Thirty percent of the total number of students in the first year at each school were sampled, and the minimum sampling unit was the class. A total of 136,266 students completed the questionnaire.

The subjects were divided into two groups according to the results of the measurement of suicidal ideation (as below).

\section{Procedure}

The survey was supported by cooperative schools, which organized the centralized questionnaire. All investigators were trained before the investigation. The questionnaire survey was conducted through the survey website (designed by the research group). Each student was assigned a unique identification code. Before each formal test, the investigators first performed a website set up beside the subject to ensure that the network was trouble-free. The standard operating instructions were placed in front of each computer. The instructions of the survey were displayed on the first page of the test. It took $20-30 \mathrm{~min}$ to fill in the questionnaire.

\section{Data collection}

Sociodemographic information measurement: Self-reported questionnaires were used to obtain information on sociodemographic variables. Sociodemographic variables included gender, age, school type, and place of residence.

The measure of suicidal ideation: Suicidal and self-harm ideation was evaluated using the Scale of Suicidal Ideation developed by the Beijing Center for Psychological Crisis Research and Intervention according to the Beck Suicidal Ideation Scale (Li \& Phillips, 2010). Suicidal and self-harm ideation was evaluated for the previous month and year. Suicidal and self-harm ideation was assessed using four questions: (1) How often have you thought that life is meaningless over the past year? (2) How often have you wanted to die in the past year? (For example, hoping to go to sleep and never wake up) (3) How often have you thought about committing suicide or deliberately hurting yourself over the last year? and (4) How often have you thought about committing suicide or intentionally injuring yourself in the last month? All items are answered on a 4-point scale ( 0 = 'never', 1 = 'very few', 2 = 'sometimes', 3 = 'frequently'). A response of 2 or 3 to any of the four questions was considered to indicate suicidal ideation in the last year. The internal consistency of the scale was 0.870 (Kayis et al., 2016).

Measuring Internet addiction: the Chinese version of Young's Internet Addiction Test (IAT) was applied to 
evaluate Internet use in the past one year (Bian, Liu, \& Li, 2016; Yao, Chen, \& Liu, 2014b). This scale is a modified version of the IAT, which is a reliable and valid measure of the addictive use of the Internet (Roy, 2002). This test comprises 20 questions answered on a 5-point Likert scale and is validated (internal consistency, alpha $=0.851$ ) (Gosling et al., 2011). The sum of the scores for the 20 components yields a quantitative Internet use score (range: 20-100) with a cutoff of 40 points for IA (Roy, 2002).

Measuring an impulsive personality: Impulsive personality traits were evaluated using the Barratt impulsiveness scaleChinese versions (BIS-CV) developed by the Beijing Center for Psychological Crisis Research and Intervention according to the BIS-11 Scale (Lu, Jia, Xu, Dai, \& Qin, 2012). The scale consists of 30 questions, including three subscales: (1) motor impulsiveness; (2) attentional impulsiveness; and (3) nonplanning impulsiveness. All items are answered on a 5-point Likert scale. The standardized formula for converting the score of the subscale to $0-100$ points is: subscale score $=$ $[($ sum of items' score -10$) / 40]{ }^{\star} 100$; total score $=$ (sum of three subscale scores)/3. The higher the score is, the stronger the impulsivity of the participant is. The Cronbach's $\alpha$ of the total and the three subscales are between 0.77 and 0.89 , and the test-retest reliability is between 0.68 and 0.89 .

Measuring an aggressive personality: Aggressive personality traits were evaluated using the Chinese Version of the Buss \& Perry Aggression Questionnaire (AQ-CV) developed by the Beijing Huilongguan Hospital Clinical Epidemiology Research Center (Maxwell, 2007). The scale consists of 30 questions, including five subscales: (1) physical aggression; (2) verbal aggression; (3) anger; (4) hostility; and (5) self-aggression. All items are answered on a 5-point Likert scale. The standardized formula for converting the score of the subscale to $0-100$ points is: subscale score of physical aggression and hostility $=[$ (sum of subscale items scores -7$) / 28]^{*} 100$; subscale score of verbal aggression and self-aggression $=[($ sum of subscale items scores -5$) / 20]$ ${ }^{\star} 100$; subscale score of anger $=[$ (sum of subscale items scores -6$) / 24]{ }^{\star} 100$, total score of AQ-CV $=[$ (sum of all items scores -30$) / 120]{ }^{\star} 100$. The higher the score is, the stronger the aggression of the participant is. The Cronbach's $\alpha$ of the total and the three subscales is between 0.60 and 0.89 , and the test-retest reliability is between 0.54 and 0.81 .

Measuring the Eysenck personality: Eysenck personality traits were evaluated using the Eysenck Personality Questionnaire-R Short Scale For Chinese (EPQ-RSC), revised by the Department of Psychology at Peking University according to the EPQ (Qian, Wu, Zhu, \& Zhang, 2000). The scale consists of four subscales: (1) introversion-extroversion (E); (2) neuroticism (N); (3) psychoticism (P); and (4) lie (L). The scale consists of 48 items, and each subscale contains 12 items. All items are answered on a 5-point Likert scale. The T-scores of the EPQ-RSC scales between 43.3 and 56.7 are considered to be intermediate types; those between 38.5 and 43.3 or 56.7 and 61.5 are considered to be prone types; and those located below 38.5 or above 61.5 are considered to be typical types. If the score of the L-subscale is more than 60 points, the reliability of the answer might not be high (Qian et al., 2000). Therefore, the present study regarded the questionnaires with an L-subscale score of $\geq 60$ as invalid questionnaires. The reliability of the P-subscale is between 0.54 and 0.60 , and the reliability of the other three subscales is between 0.74 and 0.78 . The test-retest reliability of each subscale is 0.67 in the P-subscale, 0.88 in the Esubscale, and 0.78 in the L-subscale.

The online scales of suicidal ideation, impulsive personality traits, and aggressive personality traits were designed by our research group. Cronbach's alpha coefficient of the total scale and subscale was $>0.7$. The reliability, content validity, and structure validity were high ( $\mathrm{Li} \&$ Phillips, 2010).

\section{Statistical analysis}

Statistical analysis was performed using SAS 9.3 (SAS Institute, Cary, NY, USA) and SPSS 20.0 (IBM, Armonk, NY, USA). Continuous data were presented as means \pm standard deviations or medians (interquartile ranges). Categorical data were presented as frequencies and percentages. To evaluate the differences between adolescent students with and without suicidal ideation, continuous variables were evaluated using two-sample t-tests, and categorical variables were evaluated using chi-square or Fisher's exact tests, as appropriate. Mann-Whitney U-tests were conducted for non-parametric data. Logistic regression was performed to examine the psychosocial and demographical factors for suicidal ideation. All statistical assessments were two-tailed, and the level of significance was set at $P<0.05$.

\section{Ethics}

The study procedures were carried out in accordance with the Declaration of Helsinki. The Institutional Review Board of our university approved the study. All subjects were informed about the study, and all provided informed consent.

\section{RESULTS}

\section{Demographic and psychosocial information}

A total of 149,356 students participated in the study. After verification and screening (absence of important indicators, logic errors, extreme values, and Eysenck L-subscale $\geq 60$ points), 136,266 valid questionnaires were finally included for analysis, for an effective rate of $91.2 \%$.

The mean age was $18.6 \pm 1.9$ years. According to the questionnaire, 20,218 (14.77\%) of the adolescent students had suicidal ideation. The average score on the IAT was 32.6 \pm 10.3 . A total of $28,836(21.16 \%)$ subjects were classified as having IA (IAT score $>40$ ). The majority of participants (95.88\%) were $16-20$ years of age. In addition, $40.74 \%$ of the students' families were from cities, and $59.26 \%$ were from rural areas. The demographic characteristics and distribution of the two groups are shown in Table 1.

There were substantial differences between the students with suicidal ideation and those without. A total of $15.84 \%$ 
Table 1. Demographic and psychosocial characteristics of participants with and without suicidal ideation $(n=136,266)$

\begin{tabular}{|c|c|c|c|c|c|}
\hline Variables & $N$ & Suicidal ideation $N(\%)$ & No Suicidal ideation $N(\%)$ & \multicolumn{2}{|c|}{ Statistics $\mathrm{t}$ or $\mathrm{x}^{2} P$} \\
\hline \multicolumn{6}{|l|}{ School-type } \\
\hline Middle school & 26,688 & $6,023(22.57)$ & $20,665(77.43)$ & $1,606.57$ & $<0.0001$ \\
\hline Vocational college & 39,788 & $5,010(12.59)$ & $34,778(87.41)$ & & \\
\hline University & 69,790 & $9,095(13.03)$ & $60,695(86.97)$ & & \\
\hline \multicolumn{6}{|l|}{ Gender } \\
\hline Male & 60,047 & $8,053(13.41)$ & $51,994(86.59)$ & 157.71 & $<0.0001$ \\
\hline Female & 76,219 & $12,075(15.84)$ & $64,144(84.16)$ & & \\
\hline \multicolumn{6}{|l|}{ Age } \\
\hline 15 & 19,514 & 4,486 (22.99) & $15,028(77.01)$ & $1,237.59$ & $<0.0001$ \\
\hline $16-20$ & 111,141 & $14,847(13.36)$ & $96,294(86.64)$ & & \\
\hline $21-25$ & 4,653 & $623(13.39)$ & $4,030(86.61)$ & & \\
\hline $26+$ & 958 & $172(17.95)$ & $786(82.05)$ & & $<0.0001$ \\
\hline \multicolumn{6}{|l|}{ Homeplace } \\
\hline City & 55,517 & $7,845(14.13)$ & $47,672(85.87)$ & 30.51 & $<0.0001$ \\
\hline Rural & 80,749 & $12,283(15.21)$ & $68,466(84.79)$ & & \\
\hline \multicolumn{6}{|l|}{ Internet addiction } \\
\hline Yes & 28,836 & $8,506(29.49)$ & $20,330(70.51)$ & $6,300.96$ & $<0.0001$ \\
\hline No & 107,430 & $11,622(10.82)$ & $95,808(89.18)$ & & \\
\hline
\end{tabular}

of female students reported the presence of suicidal ideation, which was significantly higher than the rate reported in male students $\left(13.41 \%, \chi^{2}=157.71, P<0.0001\right)$. The prevalence of suicidal ideation was also higher among students who came from middle schools $\left(\chi^{2}=1,606.57\right.$, $P<0.0001)$ and with relatively younger age $\left(\chi^{2}=1,237.59\right.$, $P<0.0001)$. At the same time, compared with those without IA, students with IA had a higher prevalence of suicidal ideation $\left(\chi^{2}=6,300.96, P<0.0001\right)$.

\section{Impulsive personality traits}

The total score on the BIS-CV varied from 0 to 100 , with a median of 34.16 (Q1: 25.83, Q3: 43.33). As shown in Table 2, whether or not accompanied by IA, compared with the group without suicidal ideation, the group with suicidal ideation showed higher total scores of the BIS-CV scale $(Z=28.15$,
$P \leq 0.0001)$. No planning impulsiveness $(Z=22.04, P<0.0001)$, cognitive impulsiveness $(Z=30.80, P<0.0001)$, and motor impulsiveness $(Z=34.86, P<0.0001)$ were also higher in the subscale scores. The total score of the BIS-CV scale and the scores for each subscale of students with IA were higher than those without IA (all $P<0.01$ ) (Table 2).

\section{Aggression personality traits}

The total score on the AQ-CV varied from 0 to 100 , with a median of 18.33 (Q1: 10.00, Q3: 28.33). As shown in Table 3, whether or not scores were accompanied by IA, compared with the group without suicidal ideation, the group with suicidal ideation showed a higher total score of the AQ-CV $(Z=41.54, P \leq 0.0001)$. Physical aggression $(Z=18.13$, $P<0.0001)$, verbal aggression $(Z=18.35, P<0.0001)$, anger $(Z=33.22, P<0.0001)$, hostility $(Z=42.66, P<0.0001)$,

Table 2. Descriptive statistics of impulsive personality traits (Eysenck Personality Questionnaire-R Short Scale China, EPQRSC) by the presence of suicidal ideation $(n=136,266)$

\begin{tabular}{|c|c|c|c|c|}
\hline \multirow[b]{2}{*}{ Profiles } & \multicolumn{2}{|c|}{$\mathrm{M}\left(\mathrm{Q}_{\mathrm{L}}, \mathrm{Q}_{\mathrm{U}}\right)$} & \multicolumn{2}{|c|}{ Statistics } \\
\hline & Suicidal ideation & No suicidal ideation & U-test & $P$ \\
\hline Internet addiction & $N=8,506$ & $N=20,330$ & & \\
\hline No planning impulsiveness & $52.50(42.50,62.50)^{\mathrm{a}}$ & $47.50(35.00,55.00)^{\mathrm{a}}$ & 28.15 & $<0.0001$ \\
\hline Cognitive impulsiveness & $47.50(37.50,55.00)^{\mathrm{a}}$ & $42.50(35.00,50.00)^{\mathrm{a}}$ & 22.04 & $<0.0001$ \\
\hline Motor impulsiveness & $42.50(30.00,50.00)^{\mathrm{a}}$ & $35.00(25.00,45.00)^{\mathrm{a}}$ & 30.80 & $<0.0001$ \\
\hline The total score & $47.50(39.17,54.17)^{\mathrm{a}}$ & $41.67(34.17,49.17)^{\mathrm{a}}$ & 34.86 & $<0.0001$ \\
\hline No Internet addiction & $N=11,622$ & $N=95,808$ & & \\
\hline No planning impulsiveness & $45.00(32.50,55.00)$ & $32.50(22.50,45.00)$ & 60.73 & $<0.0001$ \\
\hline Cognitive impulsiveness & $42.50(32.50,52.50)$ & $35.00(25.00,45.00)$ & 63.29 & $<0.0001$ \\
\hline Motor impulsiveness & $32.50(22.50,45.00)$ & $22.50(12.50,32.50)$ & 50.56 & $<0.0001$ \\
\hline The total score & $40.00(32.50,48.33)$ & $30.83(22.50,40.00)$ & 70.49 & $<0.0001$ \\
\hline
\end{tabular}

${ }^{\mathrm{a} C o m p a r e d ~ w i t h ~ t h e ~ g r o u p ~ o f ~ n o-I n t e r n e t ~ a d d i c t i o n, ~ M a n n-W h i t n e y ~} \mathrm{U}$ test, $P<0.01$. 
Table 3. Descriptive statistics of aggressive personality traits (Chinese Version of Buss \& Perry Aggression Questionnaire, AQ-CV) by the presence of suicidal ideation $(n=136,266)$

\begin{tabular}{|c|c|c|c|c|}
\hline \multirow[b]{2}{*}{ Profiles } & \multicolumn{2}{|c|}{$\mathrm{M}\left(\mathrm{Q}_{\mathrm{L}}, \mathrm{Q}_{\mathrm{U}}\right)$} & \multicolumn{2}{|c|}{ Statistics } \\
\hline & Suicidal ideation & No suicidal ideation & U-test & $P$ \\
\hline Internet addiction & $N=8,506$ & $N=20,330$ & & \\
\hline Physical aggression & $28.57(14.28,42.85)^{\mathrm{a}}$ & $25.00(10.71,35.71)^{\mathrm{a}}$ & 18.13 & $<0.0001$ \\
\hline Verbal aggression & $35.00(25.00,45.00)^{\mathrm{a}}$ & $30.00(20.00,40.00)^{\mathrm{a}}$ & 18.35 & $<0.0001$ \\
\hline Anger & $41.50(25.00,54.16)^{\mathrm{a}}$ & $29.00(16.66,45.83)^{\mathrm{a}}$ & 33.22 & $<0.0001$ \\
\hline Hostility & $39.00(25.00,50.00)^{\mathrm{a}}$ & $28.50(17.85,39.28)^{\mathrm{a}}$ & 42.66 & $<0.0001$ \\
\hline Self-aggression & $30.00(20.00,45.00)^{\mathrm{a}}$ & $20.00(10.00,30.00)^{\mathrm{a}}$ & 48.65 & $<0.0001$ \\
\hline Total score & $35.00(25.83,45.00)^{\mathrm{a}}$ & $27.50(19.16,36.66)^{\mathrm{a}}$ & 41.54 & $<0.0001$ \\
\hline No Internet addiction & $N=11,622$ & $N=95,808$ & & \\
\hline Physical aggression & $17.85(7.14,32.14)$ & $10.71(3.57,21.42)$ & 41.62 & $<0.0001$ \\
\hline Verbal aggression & $25.00(15.00,40.00)$ & $20.00(10.00,30.00)$ & 43.30 & $<0.0001$ \\
\hline Anger & $29.16(16.66,45.83)$ & $16.66(4.16,29.16)$ & 65.54 & $<0.0001$ \\
\hline Hostility & $25.00(14.28,35.71)$ & $14.28(3.57,25.00)$ & 79.23 & $<0.0001$ \\
\hline Self-aggression & $20.00(10.00,35.00)$ & $5.00(1.00,15.00)$ & 81.75 & $<0.0001$ \\
\hline The total score & $25.00(16.66,34.16)$ & $14.16(7.50,23.33)$ & 77.99 & $<0.0001$ \\
\hline
\end{tabular}

${ }^{\mathrm{a} C}$ Compared with the group of no-Internet addiction, Mann-Whitney $\mathrm{U}$ test, $P<0.01$

and self-aggression $(Z=48.65, P<0.0001)$ were also higher in the subscale scores. The total score of the AQ-CV scale and the score for each subscale of students with IA were higher than those without IA (all $P<0.01$ ) (Table 3).

\section{Eysenck personality traits}

The score on the EPQ-P subscale varied from 36.33 to 116.27, with a median of 46.75 (Q1: 43.27, Q3: 53.71). The score on the EPQ-E subscale varied from 18.41 to 70.75 , with a median of 50.81 (Q1: 43.33, Q3: 58.28). The score on the EPQ-N subscale varied from 34.69 to 74.72 , with a median of 48.03 (Q1: 41.36, Q3: 56.37). As shown in Table 4, whether or not accompanied by IA, compared with the group without suicidal ideation, the group with suicidal ideation showed a higher EPQ-P score $(P<0.0001)$, lower EPQ-E score $(P<0.0001)$ and higher EPQ-N score $(P<0.0001)$. The score for each subscale of the EPQ of students with IA was higher than those without IA (all $P<0.01$ ) (Table 4).

\section{Univariable and multivariable analysis of suicidal ideation impact factors}

All impact factor variables were screened using single-factor non-conditional logistic regression analysis. As shown in Table 5, after adjusting for gender, age, school type, and place of residence, the factors that were significantly associated with suicidal ideation included no planning impulsiveness $(\mathrm{AOR}=1.788, P<0.0001)$, cognitive impulsiveness $(\mathrm{AOR}=1.545, P<0.0001)$, motor impulsiveness $(\mathrm{AOR}=$ $1.816, P<0.0001)$, physical aggression $(\mathrm{AOR}=1.625$, $P<0.0001)$, verbal aggression $(\mathrm{AOR}=1.414, P<0.0001)$, anger $(\mathrm{AOR}=1.469, P<0.0001)$, hostility $(\mathrm{AOR}=2.247$, $P<0.0001)$, self-aggression $(\mathrm{AOR}=2.364, P<0.0001)$, psychoticism $(\mathrm{AOR}=1.748, P<0.0001)$, introversionextroversion $(\mathrm{AOR}=0.707, P<0.0001)$, neuroticism $(\mathrm{AOR}$ $=2.528, P<0.0001)$, and IA $(\mathrm{AOR}=3.559, P<0.0001)$.

To analyze the influence of susceptible personality and IA on suicidal ideation, a multivariable unconditional logistic regression was conducted using suicidal ideation $(0=$ no, $1=$ yes) as the dependent variable and the following

Table 4. Descriptive statistics of the Eysenck personality traits (Eysenck Personality Questionnaire-R Short Scale China, EPQ-RSC) by the presence of suicidal ideation $(n=136,266)$

\begin{tabular}{|c|c|c|c|c|}
\hline \multirow[b]{2}{*}{ Profiles } & \multicolumn{2}{|c|}{ M (QL,QU) } & \multicolumn{2}{|c|}{ Statistics } \\
\hline & Suicidal ideation & No suicidal ideation & U-test & $P$ \\
\hline Internet addiction & $N=8,506$ & $N=20,330$ & & \\
\hline $\mathrm{P}$ & $57.18(50.22,64.13)^{\mathrm{a}}$ & $53.71(46.75,60.66)^{\mathrm{a}}$ & 29.75 & $<0.0001$ \\
\hline $\mathrm{E}$ & $42.83(35.85,53.30)^{\mathrm{a}}$ & $50.81(40.84,58.28)^{\mathrm{a}}$ & 20.12 & $<0.0001$ \\
\hline $\mathrm{N}$ & $63.04(56.37,68.04)^{\mathrm{a}}$ & $54.70(48.03,61.37)^{\mathrm{a}}$ & 59.93 & $<0.0001$ \\
\hline No Internet addiction & $N=11,622$ & $N=95,808$ & & \\
\hline $\mathrm{P}$ & $50.22(46.75,57.18)$ & $46.75(39.80,50.23)$ & 53.83 & $<0.0001$ \\
\hline $\mathrm{E}$ & $45.83(38.35,55.79)$ & $53.30(45.83,58.29)$ & 45.78 & $<0.0001$ \\
\hline $\mathrm{N}$ & $56.37(49.70,64.71)$ & $44.70(39.70,51.37)$ & 100.82 & $<0.0001$ \\
\hline
\end{tabular}

P: psychoticism; E: introversion-extroversion; $\mathrm{N}$ : neuroticism.

${ }^{\mathrm{a} C}$ Compared with the group of no-Internet addiction, Mann-Whitney $\mathrm{U}$ test, $P<0.01$ 
Table 5. Multivariable analysis of suicidal ideation impact factors ( $n$ $=136,266)$

\begin{tabular}{lccc}
\hline \multirow{2}{*}{ Variables } & \multicolumn{3}{c}{ Statistics } \\
\cline { 2 - 4 } & AOR & $95 \%$ CI & $P$ \\
\hline No planning impulsiveness & 1.788 & $(1.761,1.815)$ & $<0.0001$ \\
Cognitive impulsiveness & 1.545 & $(1.523,1.568)$ & $<0.0001$ \\
Motor impulsiveness & 1.816 & $(1.790,1.844)$ & $<0.0001$ \\
Physical aggression & 1.625 & $(1.601,1.649)$ & $<0.0001$ \\
Verbal aggression & 1.414 & $(1.398,1.431)$ & $<0.0001$ \\
Anger & 1.469 & $(1.440,1.499)$ & $<0.0001$ \\
Hostility & 2.247 & $(2.211,2.284)$ & $<0.0001$ \\
Self-aggression & 2.364 & $(2.325,2.404)$ & $<0.0001$ \\
Psychoticism (P) & 1.748 & $(1.723,1.774)$ & $<0.0001$ \\
Introversion-extroversion (E) & 0.707 & $(0.698,0.717)$ & $<0.0001$ \\
Neuroticism (N) & 2.528 & $(2.490,2.567)$ & $<0.0001$ \\
Internet addition & 3.559 & $(3.445,3.677)$ & $<0.0001$ \\
\hline
\end{tabular}

independent variables: no planning impulsiveness, cognitive impulsiveness, motor impulsiveness, physical aggression, verbal aggression, anger, hostility, self-aggression, psychoticism, introversion-extroversion, neuroticism, and IA. Multivariable logistic regression analysis used a stepwise method (the rejection probability was 0.1 ). All statistical tests were two-tailed, and the probability of error type I was 5\%. For the convenience of interpretation during analysis, this study took the quartiles as the cutoff points, corresponding to the low, medium, high, and extreme levels of impulsivity and aggressiveness, respectively. The T-scores of the EPQ scales between 43.3 and 56.7 were considered to be intermediate types, and those between 38.5 and 43.3 or 56.7 and 61.5 were considered to be prone types, and T-scores located below 38.5 or above 61.5 were considered to be typical types.

The results of the logistic regression analysis are shown in Table 6. The factors related to suicidal ideation included no planning impulsiveness $(\mathrm{OR}=1.217,95 \% \mathrm{CI}: 1.195-1.239$, $P<0.0001$ ), hostility (OR $=1.212$, 95\% CI: $1.184-1.241$, $P=0.031)$, self-aggression $(\mathrm{OR}=1.443$, 95\% CI: $1.410-1.476, P<0.001)$, psychoticism $(\mathrm{OR}=1.126,95 \% \mathrm{CI}$ : 1.106-1.145, $P<0.0001$ ), introversion-extroversion (OR = 0.782, 95\% CI: $0.770-0.793, P<0.0001)$, neuroticism (OR $=$ $1.848,95 \%$ CI: $1.814-1.883, P<0.0001)$, and IA (OR $=1.185$, 95\% CI: 1.141-1.231, $P<0.0001)$. Cognitive impulsiveness, motor impulsiveness, physical aggression, verbal aggression, and anger were excluded from the stepwise regression model.

\section{DISCUSSION}

This study assessed the impact of IA, susceptible personality traits (such as neuroticism, psychoticism, extraversion, impulsiveness, and aggression), and suicidal ideation and examined the probabilistic relationships among these variables. It used a large sample of 136,226 adolescent students from 63 Chinese schools. The results suggest that IA and susceptible personality traits are risk factors for suicidal ideation among adolescent students. These results strongly suggest the importance of prevention efforts to improve personality traits and reduce IA as a means of lessening suicidal ideation.

There were 20,128 adolescent participants with suicidal ideation, with a detection rate of $14.77 \%(20,128 / 136,266)$. This finding is similar to the results of previous domestic and foreign studies (Fu et al., 2010; Schilling et al., 2009). The rate of suicidal ideation among students with IA was $29.49 \%$, which was higher than the rate of $10.81 \%$ among students without IA. The rate of suicidal ideation in females within the past year was higher than that among males. This finding is also similar to the results by Fu et al. (2010). Although the death rate from suicide is usually higher in males than in females, suicidal ideation is usually more common in females than in males (Yang et al., 2010).

Of the 136,266 students, IA in the past month was observed in $21.16 \%(28,836 / 136,266)$, a rate similar to those reported in other domestic and foreign studies (Ko, Yen, Liu, Huang, \& Yen, 2009; Shaw \& Black, 2008). IA was more common in males than in females, similar to domestic studies (Cao \& Su, 2007; Kim et al., 2006). The presence of IA among ordinary middle-school students was higher than that among the other types of students. In other words, younger students were more likely to suffer from IA, as supported by a previous study (Ko et al., 2009). IA was more prevalent among students from urban families than among rural students. This difference might be because urban students have access to the Internet more easily and spend more time online. IA has a close relationship with suicidal

Table 6. Logistic regression analysis of impact factors of adolescent students with suicidal ideation

\begin{tabular}{lccrrrr}
\hline Factors & $\mathrm{B}$ & $\mathrm{SE}$ & Wald & OR & $95 \%$ CI & $P$ \\
\hline No planning impulsiveness & 0.1963 & 0.00922 & 453.5259 & 1.217 & $(1.195,1.239)$ & $<0.0001$ \\
Hostility & 0.1924 & 0.0120 & 259.0757 & 1.212 & $(1.184,1.241)$ & $<0.0001$ \\
Self-aggression & 0.3666 & 0.0116 & $1,006.9500$ & 1.443 & $(1.410,1.476)$ & $<0.0001$ \\
P & 0.1184 & 0.00885 & 179.0773 & 1.126 & $(1.106,1.145)$ & $<0.0001$ \\
E & -0.2464 & 0.00753 & $1,069.5469$ & 0.782 & $(0.770,0.793)$ & $<0.0001$ \\
N & 0.6143 & 0.00946 & $4,218.5492$ & 1.848 & $(1.814,1.883)$ & $<0.0001$ \\
IA & 0.1699 & 0.0195 & 76.0486 & 1.185 & $(1.141,1.231)$ & $<0.0001$ \\
\hline
\end{tabular}

P: psychoticism; E: introversion-extroversion; N: neuroticism; IA: Internet addiction. 
ideation and suicidal behavior (Kayis et al., 2016). The present study found that IA is associated with suicidal ideation. The EPQ assessment of students with IA and suicidal ideation showed that they had high psychoticism in the P-subscale, high neuroticism in the E-subscale, and low extroversion in the $\mathrm{N}$-subscale.

The present study revealed that susceptibility personality traits have an impact on IA, and some personality traits are not only significantly related to IA but also have predictive power for IA. Some studies have shown that an impulsive personality, an aggressive personality, extraversion, neuroticism, and psychoticism were potential impact factors of IA (Gosling, Augustine, Vazire, Holtzman, \& Gaddis, 2011; Kayis et al., 2016; M. Z. Yao, He, Ko, \& Pang, 2014a; Y. Yao, Chen, \& Liu, 2014b). This study found that students with IA have impulsiveness and aggressiveness, suggesting that IA might be a disease with abnormal impulse control, which is consistent with a previous study (Ai et al., 2011). In this study, the impact factors related to suicidal ideation included no planning impulsiveness only regarding the impulsiveness personality traits. The other impact factors included hostility and self-aggression among aggressive personality traits. There are many reasons for higher impulsiveness and aggressiveness in students with IA. Many studies observed that online games are one of the most important factors contributing to adolescent violence (Whang, Lee, \& Chang, 2003), especially games and videos with violent content. The study also found that in the EPQ scale, the scores of the P- and E-subscales of students with IA were significantly higher than those without IA, while the scores of the N-subscale of students with IA were significantly lower than those without IA.

The present study showed that students with suicidal ideation not only had impulsiveness characteristics but also showed higher levels of aggressive behavior. Some studies found that impulsiveness is an independent risk factor for suicide ideation (Levinson, Haklai, Stein, Polakiewicz, \& Levav, 2007). Impulsiveness is an important impact factor for action by people with suicidal ideation (Conner, Meldrum, Wieczorek, Duberstein, \& Welte, 2004), which is consistent with the results of the present study and indicating that an impulsive personality is closely related to suicide. Therefore, it can be concluded that suicide is the result of the interaction between the impulsiveness and aggressiveness of individuals (McGirr et al., 2007). The stepwise logistic analysis found that only non-planning impulsiveness had a predictive effect on suicidal ideation in an impulsive personality, while in an aggressive personality, hostility and self-aggression had a predictive effect on suicidal ideation. The results also showed that high levels of psychoticism and neuroticism were impact factors for suicidal ideation, but that extroversion was a protective factor, which is consistent with previous studies (Brezo, Paris, \& Turecki, 2006; Farmer et al., 2001; Perroud et al., 2013). People with high psychoticism tend to not care about others, to be eccentric, to lack compassion, to be often hostile to people, and to have certain aggressive tendencies. In the face of difficulties and setbacks, they tend to use defense methods that are more immature and with bad coping styles, including hostility, transfer attacks, and even extreme ways to solve their problems, which may ultimately lead to suicidal ideation and even suicide. People with high neuroticism are unstable and irritable. In the context of passion, they are prone to overreact to stimuli, respond more negatively, and tend to have anxiety and depression, which may lead to suicidal ideation and suicidal behavior. When confronted with negative life events or setbacks, the coping styles of those with high extroversion tends to be more diversified. They tend to respond positively, flexibly, and rationally and are good at using external rich social resources to help them cope with setbacks. Thus, negative emotions can be promptly processed, thereby reducing the occurrence of suicidal ideation.

Overall, personality is an important and relatively stable impact factor for suicide. Different personality traits may have an independent direct effect on suicide. Personality may also affect suicide by mediating the interaction of different personality traits or other psychological traits. Previous studies on the relationship between personality traits and suicidal influence have generally assessed only a single personality trait among susceptibility personality traits. However, different personality traits overlap and interact with each other. This correlation may affect the effectiveness of certain personality traits on suicide. Different personality traits may have an independent direct effect on suicide and may also be related to other personality traits that have direct effects on suicide and play an indirect role in suicide. Therefore, the study of individual personality traits cannot compare the contribution of different personality traits to the prediction of suicide (Enns, Cox, \& Inayatulla, 2003).

\section{STRENGTHS AND LIMITATIONS}

There are certain strengths in the present research. First, this is a large cross-sectional study investigating IA and suicidal ideation using a large sample of 136,226 adolescent students from 63 Chinese schools. Second, it is one of the few studies examining and comparing the correlation between IA, susceptible personality traits, and suicidal ideation in an adolescent student group. Third, this is one of the very few studies examining personality disorders with three scales simultaneously, instead of using a screening scale only when analyzing the association with IA and suicidal ideation.

Nevertheless, the findings of this study should also be interpreted, considering several limitations. First, it was a cross-sectional epidemiological investigation. Therefore, such a study design did not permit the investigation of any causal relationship of the outcome with the exposures; it was not possible to tell whether IA preceded suicidal ideation or the other way around. Second, it used questionnaires that depended on subjective memory. Therefore, recall bias related to IA and suicidal ideation may have been present. 
Moreover, information bias and the limitations of the objective measurements related to IA, susceptible personality, and suicidal ideation may have been present. Third, cultural factors may have influenced the students' willingness to report the presence of suicidal ideation, as in China, suicidal ideation is usually regarded as undesirable, especially among adolescents (Tang \& Qin, 2015). Each culture has a unique view of death and suicide and hence of suicidal ideation. Therefore, since only Chinese students were evaluated, the results might only be suitable for them. Additional studies are necessary for other cultures. Fourth, the DSM-5 was released in 2013, while the present study started in 2012, and the questionnaire setting did not take into account this new diagnostic name that came later. Finally, this large-scale study was originally intended as a psychological screening of students, in part to detect mental disorders and further interventions based on severity. This was a wide-scale survey of real-world students in China. No psychological or psychiatric evaluation could be made in such a context. It was decided that no question about psychiatric diagnosis could be asked because of the high probability of under-reporting that could not be verified. We cannot rule out the possibility that a proportion of self-injurious behavior is the result of an underlying and preexisting mental disorder. The present study was the first step (characterizing the study population) of a research program aiming at improving the mental health of students in China. A variety of measures were then put in place for systematic intervention or formal diagnosis and treatment of at-risk students. A study is currently underway to examine the impact of these systematic measures on the prevention and control of psychiatric diseases in this cohort.

\section{CONCLUSIONS}

This study contributes new findings referring to the relationships among IA, personality disorders, and suicidal and self-harm ideation. The results suggest that IA and susceptible personality traits are important impact factors for suicidal and self-harm ideation in adolescent students. Moreover, this study demonstrates that susceptible personality (such as high psychoticism, high neuroticism, and low extroversion) play a prominent role in influencing the probability of having suicidal behavior among those recently exposed to IA. Finally, it would be desirable that efforts be made to understand the investment needed to work with students with IA and personality disorders and to address the need for such efforts to be included in programs focused on suicide prevention and mental health promotion in adolescent students.

Funding sources: Medicine Scientific Research Fund for Chongqing Health and Family Planning Committee (2018QNXM014, 2017MSXM016), Natural Science Fund from Chongqing Science and Technology Commission (cstc2018jcyjAX0164), the Scientific Research and
Cultivation Project of the First Affiliated Hospital of Chongqing Medical University (PYJJ2018-20), and the National Natural Science Foundation of China (81671360).

Authors' contribution: LK and WW conceived and supervised the study; LK, MA, JMC and $\mathrm{YH}$ designed experiments; WW, XC, JC and ZL performed experiments; JC, LK, WW analyzed data; LK, MA, WW, and JMC wrote the manuscript; JC and $\mathrm{YH}$ made manuscript revisions. All authors reviewed the results and approved the final version of the manuscript.

Conflict of interest: The authors declare no conflict of interest

\section{REFERENCES}

Ai, M., Chen, J. M., \& Wangf, M. J. (2011). The impulsiveness and aggression among suicide attempters in college students. Chinese Journal of Nervous and Mental Diseases, 37, 650-655.

Bian, H. Y., Liu, Y., \& Li, N. (2016). Meta-analysis for Internet addiction rate among adolescents. Chinese Journal of School Health, 37(1), 67-70.

Brezo, J., Paris, J., \& Turecki, G. (2006). Personality traits as correlates of suicidal ideation, suicide attempts, and suicide completions: A systematic review. Acta Psychiatrica Scandinavica, 113(3), 180206. https://doi.org/10.1111/j.1600-0447.2005.00702.x.

Cao, F., \& Su, L. (2007). Internet addiction among Chinese adolescents: Prevalence and psychological features. Child: Care, Health and Development, 33(3), 275-281. https://doi.org/10. 1111/j.1365-2214.2006.00715.x.

Conner, K. R., Meldrum, S., Wieczorek, W. F., Duberstein, P. R., \& Welte, J. W. (2004). The association of irritability and impulsivity with suicidal ideation among 15- to 20-year-old males. Suicide and Life-Threatening Behavior, 34(4), 363-373. https:// doi.org/10.1521/suli.34.4.363.53745.

Diomidous, M., Chardalias, K., Magita, A., Koutonias, P., Panagiotopoulou, P., \& Mantas, J. (2016). Social and psychological effects of the internet use. Acta Informatica Medica, 24(1), 6668. https://doi.org/10.5455/aim.2016.24.66-68.

Dumais, A., Lesage, A. D., Lalovic, A., Seguin, M., Tousignant, M., Chawky, N., et al. (2005). Is violent method of suicide a behavioral marker of lifetime aggression? American Journal of Psychiatry, 162(7), 1375-1378. https://doi.org/10.1176/appi.ajp. 162.7.1375.

Enns, M. W., Cox, B. J., \& Inayatulla, M. (2003). Personality predictors of outcome for adolescents hospitalized for suicidal ideation. Journal of the American Academy of Child \& Adolescent Psychiatry, 42(6), 720-727. https://doi.org/10.1097/01.CHI. 0000046847.56865.B0.

Esposito, C., Spirito, A., Boergers, J., \& Donaldson, D. (2003). Affective, behavioral, and cognitive functioning in adolescents with multiple suicide attempts. Suicide and Life-Threatening Behavior, 33(4), 389-399.

Farmer, A., Redman, K., Harris, T., Webb, R., Mahmood, A., Sadler, S., et al. (2001). The cardiff sib-pair study: Suicidal 
ideation in depressed and healthy subjects and their siblings. Crisis, 22(2), 71-73. https://doi.org/10.1027//0227-5910.22.2.71.

Fu, K. W., Chan, W. S., Wong, P. W., \& Yip, P. S. (2010). Internet addiction: Prevalence, discriminant validity and correlates among adolescents in Hong Kong. British Journal of Psychiatry, 196(6), 486-492. https://doi.org/10.1192/bjp.bp.109.075002.

Gosling, S. D., Augustine, A. A., Vazire, S., Holtzman, N., \& Gaddis, S. (2011). Manifestations of personality in online social networks: Self-reported facebook-related behaviors and observable profile information. Cyberpsychology, Behavior, and Social Networking, 14(9), 483-488. https://doi.org/10.1089/cyber.2010. 0087.

Heisel, M. J., Duberstein, P. R., Conner, K. R., Franus, N., Beckman, A., \& Conwell, Y. (2006). Personality and reports of suicide ideation among depressed adults 50 years of age or older. Journal of Affective Disorders, 90(2-3), 175-180. https://doi.org/ 10.1016/j.jad.2005.11.005.

Huang, Y., Kuang, L., Wang, W., Cao, J., \& Xu, L. (2019). Association between personality traits and risk of suicidal ideation in Chinese university students: Analysis of the correlation among five personalities. Psychiatry Research, 272, 93-99. https://doi. org/10.1016/j.psychres.2018.12.076.

Kayis, A. R., Satici, S. A., Yilmaz, M. F., Simsek, D., Ceyhan, E., \& Bakioglu, F. (2016). Big five-personality trait and internet addiction: A meta-analytic review. Computers in Human Behavior, 63, 35-40.

Kim, K., Ryu, E., Chon, M. Y., Yeun, E. J., Choi, S. Y., Seo, J. S., et al. (2006). Internet addiction in Korean adolescents and its relation to depression and suicidal ideation: A questionnaire survey. International Journal of Nursing Studies, 43(2), 185192. https://doi.org/10.1016/j.ijnurstu.2005.02.005.

Klonsky, E. D., May, A. M., \& Saffer, B. Y. (2016). Suicide, suicide attempts, and suicidal ideation. Annual Review of Clinical Psychology, 12, 307-330. https://doi.org/10.1146/annurevclinpsy-021815-093204.

Ko, C. H., Yen, J. Y., Liu, S. C., Huang, C. F., \& Yen, C. F. (2009). The associations between aggressive behaviors and internet addiction and online activities in adolescents. Journal of Adolescent Health, 44(6), 598-605. https://doi.org/10.1016/j. jadohealth.2008.11.011.

Levinson, D., Haklai, Z., Stein, N., Polakiewicz, J., \& Levav, I. (2007). Suicide ideation, planning and attempts: Results from the Israel national health survey. Israel Journal of Psychiatry and Related Sciences, 44(2), 136-143.

Li, Z. Z., Li, Y. M., Lei, X. Y., Zhang, D., Liu, L., Tang, S. Y., et al. (2014). Prevalence of suicidal ideation in Chinese college students: A meta-analysis. PloS One, 9(10), e104368. https://doi. org/10.1371/journal.pone.0104368.

Li, X., \& Phillips, M. R. (2010). The acceptability of suicide among rural residents, urban residents, and college students from three locations in China: A cross-sectional survey. Crisis, 31(4), 183-193. https://doi.org/10.1027/0027-5910/ a000024.

Lu, C. F., Jia, C. X., Xu, A. Q., Dai, A. Y., \& Qin, P. (2012). Psychometric characteristics of Chinese version of Barratt Impulsiveness Scale-11 in suicides and living controls of rural China. Omega (Westport), 66(3), 215-229.
Luo, M. Y. (2010). Social assessment and subdividing of after1980s. China Youth Study, 11, 32-35.

Maxwell, J. P. (2007). Development and preliminary validation of a Chinese version of the buss-perry aggression questionnaire in a population of Hong Kong Chinese. Journal of Personality Assessment, 88(3), 284-294. https://doi.org/10.1080/00223890701317004.

McGirr, A., Paris, J., Lesage, A. D., Phil, M., Renaud, J., \& Turecki, G. (2007). Risk factors for suicide completion in borderline personality disorder: A case-control study of cluster B comorbidity and impulsive aggression. Journal of Clinical Psychiatry, 68, 721-729.

Perroud, N., Baud, P., Ardu, S., Krejci, I., Mouthon, D., Vessaz, M., et al. (2013). Temperament personality profiles in suicidal behaviour: An investigation of associated demographic, clinical and genetic factors. Journal of Affective Disorders, 146(2), 246253. https://doi.org/10.1016/j.jad.2012.09.012.

Phillips, M. R., Li, X., \& Zhang, Y. (2002). Suicide rates in China, 1995-99. Lancet, 359(9309), 835-840. https://doi.org/10.1016/ S0140-6736(02)07954-0.

Qian, M., Wu, G., Zhu, R., \& Zhang, S. (2000). Development of the revised Eysenck personality questionnaire Short scale for Chinese (EPQ-RSC). Acta Psychology Sinica, 32(3), 317-323.

Roy, A. (2002). Family history of suicide and neuroticism: A preliminary study. Psychiatry Research, 110(1), 87-90.

Schilling, E. A., Aseltine, R. H., , Jr., Glanovsky, J. L., James, A., \& Jacobs, D. (2009). Adolescent alcohol use, suicidal ideation, and suicide attempts. Journal of Adolescent Health, 44(4), 335-341. https://doi.org/10.1016/j.jadohealth.2008.08.006.

Shaw, M., \& Black, D. W. (2008). Internet addiction: Definition, assessment, epidemiology and clinical management. CNS Drugs, 22(5), 353-365. https://doi.org/10.2165/00023210-200822050-00001.

Tang, F., \& Qin, P. (2015). Influence of personal social network and coping skills on risk for suicidal ideation in Chinese university students. PLoS One, 10(3), e0121023. https://doi.org/10.1371/ journal.pone.0121023.

Thompson, R., Proctor, L. J., English, D. J., Dubowitz, H., Narasimhan, S., \& Everson, M. D. (2012). Suicidal ideation in adolescence: Examining the role of recent adverse experiences. Journal of Adolescence, 35(1), 175-186. https://doi.org/10.1016/ j.adolescence.2011.03.003.

Wang, Z., Yu, G., \& Tian, X. (2018). Exploring behavior of people with suicidal ideation in a Chinese online suicidal community. International Journal of Environmental Research and Public Health, 16(1). https://doi.org/10.3390/ ijerph16010054.

Wang, W., Zhou, D. D., Ai, M., Chen, X. R., Lv, Z., Huang, Y., et al. (2019). Internet addiction and poor quality of life are significantly associated with suicidal ideation of senior high school students in Chongqing, China. PeerJ, 7, e7357. https://doi.org/ 10.7717/peerj.7357.

Whang, L. S., Lee, S., \& Chang, G. (2003). Internet over-users' psychological profiles: A behavior sampling analysis on internet addiction. CyberPsychology and Behavior, 6(2), 143-150. https://doi.org/10.1089/109493103321640338.

Wong, J. P., Stewart, S. M., Ho, S. Y., Rao, U., \& Lam, T. H. (2005). Exposure to suicide and suicidal behaviors among Hong Kong 
adolescents. Social Science \& Medicine, 61(3), 591-599. https:// doi.org/10.1016/j.socscimed.2004.12.012.

Yang, D. L., Jiang, C., \& Jia, S. H. (2017). Literature review on suicide ideation and personality. Medicine \& Philosophy, 38, $39-42$.

Yang, L. S., Zhang, Z. H., Hao, J. H., \& Sun, Y. H. (2010). Association between adolescent internet addiction and suicidal behaviors. Zhonghua Liuxingbingxue Zazhi, 31(10), 1115-1119.

Yao, M. Z., He, J., Ko, D. M., \& Pang, K. (2014a). The influence of personality, parental behaviors, and self-esteem on internet addiction: A study of Chinese college students. Cyberpsychology, Behavior, and Social Networking, 17(2), 104-110. https:// doi.org/10.1089/cyber.2012.0710.
Yao, Y., Chen, D., \& Liu, M. (2014b). Study on the relationship between Internet addiction disorder with suicidal ideation and depression among a certain Pharmaceutical University in Guangdong province. Medicine in Society, 27, 83-85.

Zhang, X., Wang, H., Xia, Y., Liu, X., \& Jung, E. (2012). Stress, coping and suicide ideation in Chinese college students. Journal of Adolescence, 35(3), 683-690. https://doi.org/10.1016/j. adolescence.2011.10.003.

Zhao, J., Yang, X., Xiao, R., Zhang, X., Aguilera, D., \& Zhao, J. (2012). Belief system, meaningfulness, and psychopathology associated with suicidality among Chinese college students: A cross-sectional survey. BMC Public Health, 12, 668. https://doi. org/10.1186/1471-2458-12-668. 